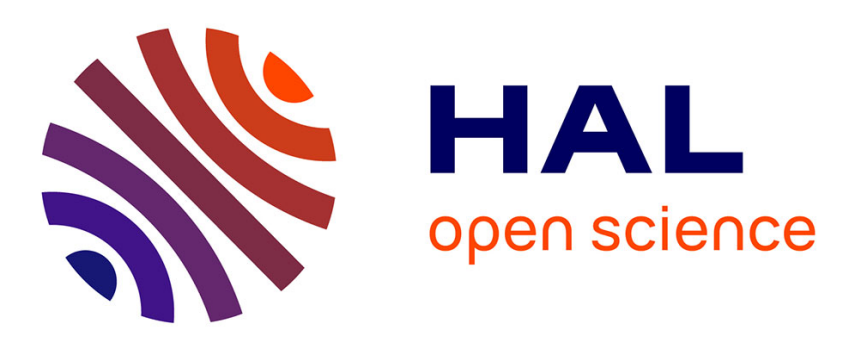

\title{
Genetic evidence of multiple introductions and mixed reproductive strategy in the peregrine earthworm Pontoscolex corethrurus
}

S. Taheri, T. Decaëns, L. Cunha, G. G Brown, E. da Silva, M. L C Bartz, D. Baretta, L. Dupont

\section{To cite this version:}

S. Taheri, T. Decaëns, L. Cunha, G. G Brown, E. da Silva, et al.. Genetic evidence of multiple introductions and mixed reproductive strategy in the peregrine earthworm Pontoscolex corethrurus. Biological Invasions, 2020, 22 (8), pp.2545-2557. 10.1007/s10530-020-02270-0 . hal-03002216

\section{HAL Id: hal-03002216 https: / hal.sorbonne-universite.fr/hal-03002216}

Submitted on 12 Nov 2020

HAL is a multi-disciplinary open access archive for the deposit and dissemination of scientific research documents, whether they are published or not. The documents may come from teaching and research institutions in France or abroad, or from public or private research centers.
L'archive ouverte pluridisciplinaire HAL, est destinée au dépôt et à la diffusion de documents scientifiques de niveau recherche, publiés ou non, émanant des établissements d'enseignement et de recherche français ou étrangers, des laboratoires publics ou privés. 

peregrine earthworm Pontoscolex corethrurus

S. Taheri ${ }^{1,2,3}$, T. Decaëns ${ }^{4}$, L. Cunha ${ }^{5,6}$, G. G. Brown ${ }^{6}$, E. Da Silva ${ }^{6}$, M. L. C. Bartz ${ }^{7}$, D.

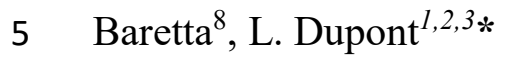

6

${ }^{1}$ Univ Paris-Est Creteil, CNRS, INRAE, IRD, IEES-Paris, F-94010 Creteil France

${ }^{2}$ Sorbonne Université, IEES-Paris, F-75005 Paris, France

9

${ }^{3}$ Université de Paris, IEES-Paris, F-75013 Paris, France

${ }^{4}$ Centre d'Ecologie Fonctionnelle et Evolutive (CEFE UMR 5175, CNRS-Université de Montpellier-Université Paul-Valéry Montpellier-EPHE), 1919 Route de Mende, F-34293 Montpellier, FRANCE

${ }^{5}$ Cardiff school of Biosciences, Cardiff University, Museum Avenue, Cardiff, UK CF10 3AX

${ }^{6}$ Embrapa Florestas, Estrada da Ribeira km. 111, Colombo, PR, 83411-000, Brazil

${ }^{7}$ Universidade Positivo, Rua Prof Pedro Viriato Parigot de Souza, 5300, CEP 81280-330, Campo Comprido, Curitiba, Parana, Brazil

${ }^{8}$ Universidade do Estado de Santa Catarina, Centro de Educaçao Superior do Oeste, Chapeco, Brazil

*Corresponding author: 1ise.dupont@u-pec.fr 
22 Keywords : founder effect, genetic diversity, parthenogenesis, recombination, soil

23 macrofauna, tropical invasive species. 


\section{Abstract}

Pontoscolex corethrurus is a well-known invasive earthworm in tropical zone which is believed to have originated from the Guayana Shield in South America and was described as parthenogenetic. A recent phylogenetic study revealed four cryptic species in the $P$. corethrurus complex (L1, L2, L3 and L4), among them L1 was particularly widespread and was proposed as $P$. corethrurus sensu stricto. Here, our aims were to investigate the genetic variation of $P$. corethrurus L1 in its presumed native and introduced ranges and to examine its reproductive strategy. An extensive dataset of 478 cytochrome oxidase I gene (COI) sequences, obtained in specimens sampled all around the world, revealed a weak COI haplotype diversity with one major haplotype (H1) present in $76 \%$ of the specimens. Analyses of the genetic variation of 12 L1 populations were done using both nuclear (226 AFLP profiles) and mitochondrial (269 COI sequences) genetic information. The high AFLP genotype diversity at the worldwide scale and the fact that no genotype was shared among populations, allowed to reject the 'super-clone' invasion hypothesis. Moreover, a similar level of mean genetic diversity indices were observed between the introduced and native ranges, a pattern explained by a history of multiple introductions of specimens from different parts of the world. At last, occurrence of identical AFLPs genotypes (i.e. clones) in several population confirmed asexual reproduction, but recombination was also revealed by gametic equilibrium analysis in some populations suggesting that $P$. corethrurus L1 may have a mixed reproductive strategy. 


\section{Introduction}

Many species have been reported as having extremely widespread distributions. Among these cosmopolitan species, earthworms are poorly represented except for a few taxa. Because of the limited dispersal ability of earthworms it is even striking that out of approximately 5358 described species according to the online Drilobase database, about 120 species are considered peregrine i.e. widely ranging, often owing to human actions (Blakemore 2009; Csuzdi 2012; Hendrix et al. 2008). Over the past centuries, global commerce has favored transport of temperate more than tropical earthworm species but Hendrix et al. (2008) alerted that the emergence of new tropical invasive species is likely. Insights into the invasiveness of earthworms in tropical regions may be gained by examining the specific attributes responsible for the success of the most well-known tropical peregrine earthworm, Pontoscolex corethrurus (Müller 1857).

This pan-tropical earthworm is believed to have originated from the Guayana Shield in South America (Righi 1984) which includes Guyana, Suriname, French Guiana, most of Southern Venezuela, as well as parts of Colombia and Brazil. A recent phylogenetic study using two mitochondrial (cytochrome c oxidase I and 16S-rDNA genes) and two nuclear (internal transcribed spacer 2 and 28S-rDNA) markers, in addition to a large-scale multilocus sequence, revealed the high complexity of the genus Pontoscolex (Taheri et al. 2018a). The commonly treated as a unique entity $P$. corethrurus was shown to correspond to a complex of four distinct species (i.e., defined as L1, L2, L3 and L4). Two highly divergent genetic lineages (L1 and L4) were already described by Cunha et al. ( 2014), using sequences of two mitochondrial genes and Amplified Fragment Length Polymorphism (AFLP) markers, in three populations of the São Miguel Island in the Azores archipelago. Taheri et al. (2018a) revealed that P. corethrurus L1 was the most widespread lineage in the world. It was present in the location where this species was first described by Fritz Müller in 1857 (Müller 1857), suggesting that L1 
corresponds to $P$. corethrurus sensu stricto. Most published studies in the past referencing " $P$. corethrurus" have probably dealt with the $P$. corethrurus $\mathrm{L} 1$ species, although the risk to have investigated another lineage is not null. P. corethrurus was described as an endogeic earthworm, tolerant to a wide range of biotic and abiotic environmental conditions (review in Taheri et al. 2018b), and reproducing parthenogenetically, although the possibility of sexual reproduction could not be ruled out (Dupont et al. 2012; Gates 1973). The mode of parthenogenesis in P. corethrurus is not well known. It is generally accepted that parthenogenetic earthworms are automictic (i.e. mode of parthenogenesis that retains meiosis) with a premeiotic doubling of the chromosome number, followed by regular meiosis which restore diploidy in the following egg (Diaz Cosin et al 2011). Because replicated chromosomes pair prior to meiosis I, the offspring are genetically identical to the mother (such as in apomictic parthenogenesis with suppression of meiosis), and heterozygosity is maintained (Simon et al. 2003, Lutes 2010). In other types of automictic parthenogenesis, diploidy is restored by duplication or fusion of the female gamete and it rapidly leads to complete homozygosity (Simon et al. 2003).

Several peregrine earthworm species are known to have a parthenogenetic reproduction often accompanied by polyploidy, in addition to some other advantageous traits such as high fecundity, small size, resistant cocoons, wide and rapid dispersal, feeding diet plasticity (reviewed in Fernandez et al. 2011a) and resistance to drought (Bartz, Brown, Decaëns \& Lapied personal observations) and to waterlogged soils (Bartz personal observation). Two main features allow parthenogenetic species to invade and establish in new habitats faster than sexually reproducing species; (i) the potential increase of the population in numbers per generation is double that of an amphimictic species and (ii) the ability of a single individual to establish a new colony (Cuellar 1977). However, the lack of recombination makes asexual lineages prone to accumulate deleterious mutations that limit their evolutionary potential. 
Mixed reproductive systems can combine the advantages of both sexual and asexual reproduction in terms of genetic load reduction, fixation of beneficial mutations, and adaptation to fluctuating environments (Bazin et al. 2014). In earthworms, mixed reproductive systems, combining parthenogenesis and amphimixis, is only known in the peregrine species Aporrectodea trapezoides. Although the most abundant clone of A. trapezoides was showed to be purely parthenogenetic, two pseudogametic (i.e. parthenogenetic reproduction requiring sperm to stimulate embryogenesis without incorporating the parental DNA) populations and two populations where amphimictic and parthenogenetic forms coexist were discovered (De Sosa et al. 2017; Fernandez et al. 2011b ).

Population genetics tools can contribute significantly to the understanding of the reproductive strategies of peregrine species (e.g. Dupont et al. 2007). The elucidation of genetic structure patterns and variation within and among populations in distant locations has also the potential to provide insights into the geographic origin, migration pathways and colonization history (e.g. single vs multiple introductions) of peregrine species (Sakai et al. 2001). For instance, molecular markers have proved to be powerful tools for inferring the evolutionary history of A. trapezoides (Fernandez et al. 2011a; Fernandez et al. 2016) which has Palearctic origin but a current worldwide distribution. Analyzing two mitochondrial and two nuclear markers, Fernandez et al (2011a) revealed a relatively high clonal diversity in this species whereas one clone was shared by almost one third of the sampled individuals and was widely distributed. Such "super-clones" are thought to be "general-purpose genotypes" (Lynch 1984) which show a broad ecological tolerance resulting from interclonal selection in temporally variable environments (Vorburger et al. 2003).

To date, only two studies focused on $P$. corethrurus population genetics and were of limited geographical scale. Dupont et al (2012) investigated the genetic variability of $P$. corethrurus in its presumed native range using AFLPs. Among the six populations from French 
122 Guiana, a higher level of genetic diversity was found in populations originating from the most

123 disturbed sites while a higher number of clones was observed in the other populations. In the

124 São Miguel Island in the Azores archipelago, Cunha et al. (2014) found a higher intra-lineage

125 genetic diversity in the population of $P$. corethrurus L1 living in pineapple greenhouses, most

126 probably because of repeated introductions. Here, our aim was to achieve a large-scale

127 population genetics study of $P$. corethrurus L1, investigating samples coming from its

128 presumed native and introduced ranges, and using cytochrome oxidase I (COI) mitochondrial

129 gene, in addition to AFLPs markers. The genetic variability and the genetic differentiation of

130 the different $P$. corethrurus L1 populations were studied in order to test the following

131 hypothesis: (i) a "super-clone" has invaded most of the introduced areas, (ii) the clonal diversity

132 is lower in the introduced range than in the native one because mutations did not have time to

133 accumulate, and (iii) this species has a mixed reproductive strategy. 


\section{Methods}

\subsection{Mitochondrial DNA analysis}

We first assessed genetic diversity and its distribution among $P$. corethrurus L1 by reanalyzing the extensive global dataset of cytochrome oxidase I (COI) sequences published in Taheri et al (2018a). Of the 662 COI sequences in Taheri et al (2018a) study, 478 belonged to P. corethrurus L1 specimens coming from a total of 49 locations belonging to five biogeographical realms (Genbank accession and information on the samples in supplementary data Table S1). In order to investigate the relationships among the different L1 haplotypes, a haplotype network was constructed based on derived haplotypes in Network v. 5.0.0.1, using median joining calculations (Bandelt et al. 1999).

For the analysis of genetic diversity at the population level, we selected 12 populations with a minimum sampling size of 9 individuals (Table 1, 269 COI sequences); 5 populations came from the presumed native range of the species (i.e. the Guayana Shield) and more precisely from French Guiana [Cayenne (CAY), Mitaraka (MIT), Pararé A (PARA), Pararé B (PARB) and Pararé C (PARC)] and 7 other populations came from the presumed introduced range represented by north and south of Brazil [Caxiuana (CAX)], Belem (BEL), Joinville (JNL), Orleans (ORL)], Mexico [Tlalcotlen (TLC)], Gabon [La Lopé (LOP)] and Thailand [Chachoengsao $(\mathrm{CHG})]$. For these populations, number of polymorphic sites, number of haplotypes, haplotype (gene) diversity and nucleotide diversity (Pi; Nei 1987) were calculated, using DnaSP v. 5 software (Librado and Rozas 2009). The historical stability of populations was assessed with a test of neutrality (Tajima's D, Tajima 1989) that also served as indicator of population expansion in DnaSP. We quantified the amount of genetic differentiation of population groups using a hierarchical Analysis of Molecular Variance (AMOVA) implemented in Arlequin V3.5 (Excoffier \& Lischer, 2010). In this analysis, the COI data set was partitioned at three levels: groups of populations from native versus introduced range, 
among-populations within groups and among all populations. One thousand random permutations were used to infer the significance of the variance components.

\subsection{Nuclear DNA analysis using AFLPs}

\subsubsection{AFLP procedure}

The genetic variation of the 12 previously described populations was also investigated using AFLP markers. DNA extraction was performed as described in Taheri et al (2018a). AFLP analysis of 226 specimens was carried out according to Vos et al. (1995) with a few modifications: approximately $50 \mathrm{ng} / \mu \mathrm{l}$ of purified genomic DNA of each specimen was digested with two digestive enzymes. The first digestion was done in $10 \mu$ l with Taq1 (20U, New England BioLabs, Ipswich, MA, USA (NEB)), Buffer Taq1 (10X, NEB), BSA (1mg.ml1, NEB) and incubated for $1 \mathrm{~h} 30$ at $65^{\circ} \mathrm{C}$ by thermal cycler (T100TM, BIO-RAD Laboratories Inc., Foster city, CA, USA). The second digestion of the DNA from the last step was done in $15 \mu 1$ with a solution of: EcoRI (20U, NEB), Buffer EcoRI (10X, NEB), BSA (1mg.ml-1, NEB) and incubated for $1 \mathrm{~h} 30$ at $37^{\circ} \mathrm{C}$. We verified DNA digestion quality by gel electrophoresis and negative controls were run at each time. Adapters were ligated using 50pmoles $\mu \mathrm{l}^{-1}$ of doublestranded Taq1 adapter (Taq top 5'-GACGATGAGTCCTGAC and Taq bottom 5'CGGTCAGGACTCAT, Eurofins Genomics, Germany) and 5pmoles $\mu \mathrm{l}-1$ of double-stranded EcoRI adapter (Eco top 5'-CTCGTAGACTGCGTACC-3' and Eco bottom 5'AATTGGTACGCAGTCTAC-3', Eurofins Genomics, Germany), T4 DNA ligase buffer (10X, Promega, Madison, WI, USA), ATP (10mM, NEB), BSA (1mg.ml-1, NEB), T4 DNA ligase (3U, Promega). Samples with a total volume of $50 \mu \mathrm{l}$ (prepared solution + digested DNA from previous step + adjusted water) was then incubated for $3 \mathrm{~h}$ at $37^{\circ} \mathrm{C}$. Digestion-ligation production of $20 \mu \mathrm{l}$ was diluted with $40 \mu \mathrm{l}$ of AE buffer (QIAGEN Sciences, Maryland, USA). Then each dilution was divided in 3 separate samples of $15 \mu 1$ each. Pre-selective PCRs 
contained 5pmoles of E01 primer (GACTGCGTACCAATTCA) and 5pmoles of T01 primer (GATGAGTCCTGACCGAA), MgCl2 (25mM, Promega), dNTPs (10mM, InvitrigenTM, Life technologies, Carlsbad, CA, USA), GoTaq buffer (5X, Promega), DNA Taq polymerase (5U, Promega), adjusted with water to have a total volume of $50 \mu \mathrm{l}$ in each sample (added to diluted ligation product). The PCR pre-selective was done by an initial denaturation step at $94^{\circ} \mathrm{C}$ for $2 \mathrm{~min}$, followed by annealing setup of 30 cycles containing; $94^{\circ} \mathrm{C}$ for $30 \mathrm{~s}, 56^{\circ} \mathrm{C}$ for $1 \mathrm{~min}$ and $72^{\circ} \mathrm{C}$ for $60 \mathrm{~s}$, and finally elongation setup of $72^{\circ} \mathrm{C}$ for 10 minutes. After this setup, the three sub samples were reassembled in one, and then $1 \mu$ of each sample was diluted in $19 \mu 1$ of AE buffer (QIAGEN). Selective PCR reactions contained $5 \mu$ l of pre-amplified DNA with $15 \mu$ of a solution containing $\mathrm{MgCl} 2$ (25mM, Promega), dNTPs (10mM, Invitrigen), GoTaq buffer (5X, Promega), 5pmoles. $\mu 1-1$ T32 primer (5'-GATGAGTCCTGACCGAAAC-3') or 5pmoles. $\mu 1-1$ T38 primer (5'-GATGAGTCCTGACCGAAACT-3'), DNA Taq polymerase (5U, Promega) and one primer combination E32-FAM was used (5'-GACTGCGTACCAATTCAA-3'). A touchdown thermal cycling (PTC-100) started with denaturing setup of $94^{\circ} \mathrm{C}$ for 2 min, following by 9 cycles; $94^{\circ} \mathrm{C}$ for $30 \mathrm{~s}, 65^{\circ} \mathrm{C}$ for $30 \mathrm{~s}$ with $1^{\circ} \mathrm{C}$ diminution per cycle, $72^{\circ} \mathrm{C}$ for $60 \mathrm{~s}$, following by 26 cycles containing $94^{\circ} \mathrm{C}$ for $30 \mathrm{~s}, 56^{\circ} \mathrm{C}$ and $72^{\circ} \mathrm{C}$ during $1 \mathrm{~min}$ and finally $72^{\circ} \mathrm{C}$ for 10 minutes. After each setup DNA solutions were centrifuged by ROTANTA 460R (Hettich Lab Technology, Tuttlingen, Germany). Amplified products were mixed with formamide (Hi_DiTM, Applied Biosystems, Foster city, CA, USA (AB) and a Genescan ${ }^{\mathrm{TM}}-500 \mathrm{LIZ}^{\mathrm{TM}}$ (AB) size standard $\left(9.5 \mu 1\right.$ of formamide and $0.5 \mu 1$ of GenescanTM-500LIZ ${ }^{\mathrm{TM}}$ for $2 \mu 1$ of amplified product). Fragments were separated on an ABI PRISM ${ }^{\mathrm{TM}} 3130$ Genetic Analyzer (platform INSERM, Henri Mondor hospital, Créteil). Raw data were visualized, and the fragments manually scored using Genemapper V5 (Applied Biosystem) software. Processed data were exported as presence/absence matrix. 
Genetic markers, including AFLPs, can be prone to genotyping errors with various potential sources (Bonin et al. 2004). Therefore, we estimated the genotyping error rate of our dataset by re-genotyping and blind scoring of 54 randomly chosen individuals. The error rate was calculated by mismatch error rate based on the formula proposed by Bonin et al. (2004), multiplied by the total number of markers.

\subsubsection{Genetic diversity analysis}

Genetic diversity statistics, including number of different genotypes by considering the 'error rate' calculated from replicates (i.e. 1.16), genotype diversity, gene diversity, proportion of variable markers and the frequency down-weighed marker value (DW, Schonswetter et al. 2005) that indicates the rarity of each marker within the dataset were calculated using AFLPdat program (Ehrich 2006). Genotype and gene diversity were calculated based on Nei's formula (Nei 1987). Similar genotypes within locations were removed and further analyses on $P$. corethrurus L1 were carried out on a dataset without clones.

\subsubsection{Multilocus gametic disequilibrium}

In order to evaluate the evidence for recombination, measures of multilocus gametic disequilibrium were calculated and tested for significance with 500 randomizations in Multilocus software (http://www.bio.ic.ac.uk/evolve/software/multilocus/), using 3 different methods. First, we performed a character compatibility analysis. In a data set with a bi-allelic marker with presence or absence ( 1 or 0$)$ at each locus such as AFLPs, the presence of all four possible combinations of alleles at two different loci (e.g. 0/0,1/0,0/1, 1/1) is an indirect signal of recombination. In contrast, a hierarchical data structure (e.g. 0/0, 0/0, 1/1, 1/1) fits to a model of mutations that are vertically transmitted and accumulated within a clonal lineage. The proportion of compatible pairs of loci was thus computed to probe the predominant mating 
system in the populations. Moreover, the index of association $\left(\mathrm{I}_{\mathrm{A}}\right)$ and an alternative measure of index of association that is less sensitive to the number of loci ( $\bar{r}_{\mathrm{d}}$, Agapow and Burt 2001) were computed. We further tested for gametic disequilibrium based on the distribution of allelic mismatches between pairs of genotypes over all loci using an exact test implemented in Arlequin. To adjust for multiple comparisons, the SGoF method (Carvajal-Rodriguez et al. 2009) as implemented in the software Myriad (http://myriads.webs.uvigo.es/MyriadsReadme.htm) was applied.

\subsubsection{Genetic structure among populations}

Analysis of molecular variance (AMOVA) was conducted in Arlequin V3.5 in the same way as for the COI dataset. In addition, an unbiased estimate of differentiation among populations, $\theta^{(\mathrm{II})}$ was obtained using the Bayesian method proposed by Holsinger et al. (2002) and implemented in the software Hickory v1.1. The data were run with the default parameters using the f-free model.

To illustrate the relationships among populations, a split network was constructed using the software Splitstree version 4.1.4.6 (Huson and Bryant 2006) on AFLP profiles. We used the distance-based Neighbor-Net (N-net) method for construction of networks. The N-net provides good visualization of the data when it presents complex evolutionary steps or reticulate relationship among genotypes (Huson and Bryant 2006). The networks were constructed based on Nei's distance (GD) matrix between populations calculated with a Bayesian method using AFLP-Surv version 1.0 (Vekemans et al. 2002) with non-uniform distribution by assuming deviation from Hardy-Weinberg equilibrium; $F_{\text {is }}$ values were estimated by Hickory software using the full model ( $f=0.033$, Holsinger et al. 2002). Analyses were done with 1000 permutations and 1000 bootstrap values. 


\section{Results}

\subsection{COI genetic variation}

An extensive global dataset of COI sequences obtained in L1 specimens was used to assess the distribution of mitochondrial genetic diversity among populations. Thirteen COI haplotypes were inferred from 478 sequences within 49 locations. COI haplotype network is shown in Figure 1. Haplotype one was shared by most individuals i.e., 364 out of 479, followed by haplotype two with 64 individuals. Five haplotypes (i.e., H3, H7, H8, H9, and H10) were exclusively found in the presumed native range while six haplotypes were found exclusively in the presumed introduced range $(\mathrm{H} 4, \mathrm{H} 5, \mathrm{H} 6, \mathrm{H} 11, \mathrm{H} 12$ and $\mathrm{H} 13)$. In 5 populations (PARA, PARB, PARC, ORL and LOP), no polymorphic site was observed. In the native range, the highest values of COI genetic diversity indices were obtained in the MIT population (Table 1) with 10 polymorphic sites and a haplotype diversity of 0.693 . In the introduced range, the highest COI genetic diversity was observed in CAX (11 polymorphic sites, haplotype diversity of 0.561 ). No difference of mean haplotypic diversity was observed between the native (mean gene diversity $=0.24, \mathrm{SD}=0.46)$ and the introduced (mean gene diversity $=0.26, \mathrm{SD}=0.32$ ) ranges (2-tailed test, $\mathrm{t}=-0.07, \mathrm{p}=0.943)$.

The null hypothesis of neutrality was rejected due to significant negative value in the BEL population indicating a recent population expansion in this location. Positive and significant Tajima's D tests were obtained in the CAY and MIT populations indicating population sub-structure in these sites. AMOVA analysis showed that $64 \%$ of the genetic variation was partitioned among all populations, $25 \%$ was attributed to differences among populations within groups, and $11 \%$ of the variation was due to differences between native and introduced groups (Table 2). The genetic differentiation among the native and introduced 
groups $\left(\Phi_{\mathrm{CT}}\right)$ was not significant while the genetic differentiation among all populations was important $\left(\Phi_{\mathrm{ST}}=0.361, \mathrm{P}<0.001\right)$.

\subsection{AFLPs genetic variation}

A total of 394 AFLPs loci were scored and among them 318 were polymorphic. The difference between the number of individuals analyzed using AFLPs and the number of different AFLP genotypes in the dataset indicates the number of clones in each population. High number of clones (85\%) were found in LOP location (Gabon) with 17 similar genotypes out of 20 individuals (Table 1). Important proportion of clones was also observed in CHG (Thailand) with 10 similar genotypes out of 35 individuals (29\%) and in CAX (Brazil) with 4 similar genotypes out of 18 individuals (22\%). In five populations i.e., CAY, PARC, BEL, JNL, and TLC, no clones were found. The highest rates of rare alleles were observed in CAY, MIT, CAX and LOP with DW values of 1804, 830.7, 708.9 and 692.7, respectively. The smallest DW values were found in JNL and PARA with 354.1 and 362.2 values respectively.

Further analyses were done on data set without clones, reducing the dataset from 226 profiles to 185 . The highest gene diversity was found in JNL, CAY and PARC $(0.168,0.165$ and 0.163 respectively) while the lowest values were obtained in LOP, PARA, PARB and ORL $(0.012,0.052,0.083$ and 0.087 respectively, Table 1$)$. No difference of mean gene diversity was observed between the native (mean gene diversity $=0.12, \mathrm{SD}=0.01$ ) and the introduced (mean gene diversity $=0.11, \mathrm{SD}=0.01)$ ranges $(2$-tailed test, $\mathrm{t}=0.269, \mathrm{p}=0.793)$.

All indices of multilocus gametic disequilibrium were congruent (Table 1). All populations showed significant gametic disequilibrium and character compatibility (except LOP but the analysis couldn't be correctly carried out in this population because an extremely low polymorphism) as expected in an asexually reproducing parthenogenetic species. However, the values of these indices were highly different among populations. Thus, the TLC population 
showed a particularly high value of index of association $\left(I_{A}=42.52\right)$ while the lowest significant value was obtained in $\mathrm{JNL}\left(\mathrm{I}_{\mathrm{A}}=2.23\right)$. variation was partitioned within populations, $31 \%$ was attributed to differences among populations within groups, and $5 \%$ of the variation was due to differences between the native 313 and introduced groups. All three hierarchical levels were significant with $\mathrm{P}<0.05$ (Table 2) but 314 the genetic differentiation among groups was low $\left(\Phi_{\mathrm{CT}}=0.052, \mathrm{P}=0.001\right)$. A similar level of genetic differentiation among populations was obtained using the f-free model with Hickory software: $\theta^{(\mathrm{II})}=0.342$. Relationships between populations are illustrated by the Neighbor-Net

317 results obtained from Nei's genetic distances (Fig. 2, supplementary data Table S2): LOP and 318 CAY were the most differentiated to each other and to the other locations while the sample from Asia $(\mathrm{CHG})$ was genetically close to the populations from South America. Moreover, all populations from the native range were grouped together. 


\section{Discussion}

323

\section{The "super-clone" hypothesis}

Despite the very extensive geographical range of $P$. corethrurus in the tropical and subtropical zone, and the limited potential for natural dispersal of earthworms (Costa et al., 2013), our sampling of Africa, Asia, South America and Central America and various islands revealed a low global mitochondrial haplotypic diversity with a total of 13 COI haplotypes and, among them, three major haplotypes (H1, H2 and H3). These haplotypes were not very divergent: $\mathrm{H} 1$ was only separated from $\mathrm{H} 2$ by four mutations and by six mutations from H3. The haplotype H1 was observed in all continents and was in high frequency in the introduced populations. All populations from the presumed native range showed the $\mathrm{H} 1$ haplotype and it was the sole haplotype in three of them (PARA, PARB and PARC). The haplotype H2 was also frequent in both native and introduced ranges but was absent from Africa while the haplotype H3 was only observed in two populations (MIT and CAX). These results could suggest that $\mathrm{H} 1$ and $\mathrm{H} 2$ correspond to "super-clones" such as those observed in aphids. For instance, population studies of the parthenogenetic aphid Myzus persicae revealed that some genotypes are widespread both in time and space (Vorburger et al. 2003). It was proposed that these predominant genotypes possess general-purpose genotypes, i.e. genotypes with broad ecological tolerances as a result of interclonal selection in temporally variable environments (Lynch 1984). In the case of $P$. corethrurus, a successful invasive earthworm species that has a pan-tropical distribution, this postulate was appealing and was tested through our population genetic study using AFLP markers. Although clones were observed in several populations and sometimes in high frequency, no AFLP profile was shared among populations. For instance, the LOP population that had the highest number of clones, had a high DW value, meaning that the AFLP genotypes within this population were highly different from the other genotypes of the total dataset. Overall, AFLP results allow to reject the hypothesis that a "super-clone" was responsible for 
the success of $P$. corethrurus invasion. The most likely factors that may be suggested to explain the lack of COI haplotype diversity in P. corethrurus populations are a slow evolutionary rate of the COI gene (i.e. constraint on the ability of the mitochondrial genome to accumulate mutations) or, more likely, genetic drift associated with historical events, such as recent population bottlenecks or founder effects (e.g. López-Legentil \& Turon, 2007). The fourfold higher effective population size for the nuclear genome compared to mitochondrial loci, which results in genetic drift being four times weaker for nuclear loci may explain the discrepancy between the mitochondrial genetic depletion and the relatively high genetic variability of the nuclear loci.

\section{Genetic variation in introduced versus native range}

The number of COI haplotypes was slightly higher in the presumed introduced range per comparison with the presumed native range ( 9 and 7 respectively), and comparison of mean haplotypic diversity values between populations from the native and introduced ranges showed no significant difference. This is explained by the fact that the COI haplotypic diversity was highly variable among populations. Within the native range, several populations did not show any COI polymorphism while other populations displayed some of the highest values of COI diversity of the dataset (Table 1, Fig 1). Similar patterns of discordant genetic diversity among populations from the native range was observed with the nuclear markers; AFLPs gene diversity was two to three times higher in CAY and PARC populations per comparison with PARA and PARB. The congruence between AFLPs and mitochondrial data suggests that the low COI polymorphism of this species is not due to a marker-specific effect but most probably due to population and species history.

Strong genetic drift effects are expected when populations are founded by a small number of colonists (Sakai et al. 2001). Our data for P. corethrurus fit this theoretical expectation in the LOP population where an extremely low AFLP genetic diversity was 
observed, congruent with the lack of COI polymorphism (Table 1). Except the LOP population, which was probably very recently founded, levels of genetic variation measured from AFLP data in introduced populations were comparable to those found in populations from the presumed native range (Table 1). For instance, the JNL population (Brazil) showed high gene diversity (0.168) comparable to those of CAY (0.165). Moreover, no enhanced genetic differentiation, except for the specific case of LOP, was observed in the introduced range although repeated founder effects are likely to increase genetic divergence among populations (Slatkin 1977). The absence of reduced genetic diversity in most of the introduced range is also certainly a result of $P$. corethrurus rapid population expansion (e.g. Zenger et al. 2003). The signature of population expansion is, for instance, still visible in the population of Belem where a negative and significant Tajima's D value was obtained. Moreover, it is noteworthy that the native range of the species is not known with certainty. In particular, the case of Northern Brazilian sites (CAX and BEL) is tricky. We hypothesized that they correspond to the introduced range because they do not belong to the Guayana Shield but they might also correspond to the native area.

Our results suggest that successive introduction from multiple sources has enhanced genetic diversity in not only some introduced localities but also in the presumed native range. Significant sub-structures were indeed revealed by positive and significant Tajima's D value in two populations of the native range (i.e. CAY and MIT). A previous study has already showed that the suburban environment of Cayenne, where the CAY population was sampled, is prone to constant introduction of individuals (Dupont et al. 2012). In the locality of Mitaraka (MIT population) situated in the Amazonian primary forest where human activity is extremely limited, the explanation could be completely different. In this locality, specimens were collected in five different sub-localities (supplementary data Table S1) separated by a maximum of $3 \mathrm{~km}$. This distance is therefore probably sufficient to detect sub-structure using AFLP markers, 
highlighting the low active dispersal of the species. At the opposite, in more disturbed sites, passive dispersal linked to human activities is probably the predominant mode of spread (Dupont et al. 2012). In South America, successive introduction and rapid expansion through passive dispersal could be occurring since humans arrived and dispersed in Amazonia (Cunha et al. 2016).

\section{The mixed reproductive strategy of Pontoscolex corethrurus sensu stricto}

P. corethrurus has several life history traits that predispose it to invasiveness (Taheri et al. 2018b). Among them, the ability of a single individual to establish a population is an important characteristic of several invasive species. (Dybdahl and Drown 2011). The important number of clones revealed in some populations by the AFLP analysis highlights the prominence of parthenogenetic reproduction in this species. For instance, in LOP only $15 \%$ of the AFLP genotypes were different. The importance of asexual reproduction is also confirmed by the high levels of gametic disequilibrium (Table 1) that were observed in several populations such as $\operatorname{TLC}\left(\mathrm{I}_{\mathrm{A}}=42.52 ; \bar{r}_{\mathrm{d}}=0.39\right), \operatorname{CAX}\left(\mathrm{I}_{\mathrm{A}}=22.34 ; \bar{r}_{\mathrm{d}}=0.12\right), \operatorname{PARB}\left(\mathrm{I}_{\mathrm{A}}=18.51 ; \bar{r}_{\mathrm{d}}=0.21\right)$ and $\operatorname{ORL}\left(\mathrm{I}_{\mathrm{A}}=13.37 ; \bar{r}_{\mathrm{d}}=0.16\right)$.

Although asexual reproduction provides an immediate demographic advantage, it is expected that in the long term, asexual populations deteriorate in fitness due to mutation accumulation or the inability to cope with changing environment (Lynch et al. 1993; Muller 1932). Thus, asexual lineages depend on occasional sexual recombination to add variation to their genomes, purge deleterious mutations, and adapt to changing environments. A mixed strategy of asexual reproduction with low level of sex combines the best of both strategies (Combosch and Vollmer 2013; Hurst and Peck 1996). It has been previously suggested that $P$. corethrurus was capable of such a mixed reproductive strategy (Dupont et al. 2012; Gates 1973; 
Taheri et al. 2018b) and this hypothesis was tested here using the AFLP genotypes. We showed that low values of gametic disequilibrium estimators in some populations (e.g. $\mathrm{I}_{\mathrm{A}}=2.23 ; \bar{r}_{\mathrm{d}}=$ 0.01 and $\mathrm{I}_{\mathrm{A}}=2.54 ; \bar{r}_{\mathrm{d}}=0.01$ in JNL and PARC populations respectively, Table 1) associated to an absence of clones revealed the occurrence of recombination within these populations. Meiotic recombination occurs during amphimictic reproduction and automictic parthenogenesis. Because recombination occurs between sister chromosomes in the premeiotic doubling of chromosome happening before the regular meiosis of the automictic parthenogenesis (i.e. the type of parthenogenesis described in earthworms), gametic disequilibrium is not expected in this case. Although we cannot exclude that another type of automictic parthenogenesis occurs in P. corethrurus, our results seem to support the hypothesis previously proposed of a plastic reproduction strategy in $P$. corethrurus.

\section{Conclusion}

Successive founder effects and demographic bottlenecks are most probably responsible of the low COI genetic diversity revealed in our worldwide scale study. Although mtDNA contain historic genetic mutations and is suitable for resolving taxonomic uncertainties, AFLP markers are more appropriate for inferring contemporaneous genetic patterns. Comparing results obtained using both kind of markers revealed that the founder event in LOP was probably more recent than in the other populations where COI polymorphism was also null (PARA, PARB, PARC and ORL). A major question in invasion biology is how newly founded and subsequently isolated populations overcome the detrimental effects of low genetic diversity, the so-called 'genetic paradox' (Allendorf and Lundquist 2003; Roman and Darling 2007). The establishment success of newly founded P. corethrurus populations may be due to recurrent introductions from multiple sources, accumulation of new mutations and high level of intrinsic phenotypic plasticity (i.e. Taheri et al. 2018b), in addition to a mixed reproductive 
strategy. Asexual reproduction improves $P$. corethrurus ability to reach high abundance (e.g.

447 Taheri et al. 2018b) and is a particularly important trait in the first stage of the invasion, when 448 sexual partners are rare. During establishment and expansion of the population, events of sexual 449 reproduction will then promote the genetic diversity. Such a mixed reproductive strategy is a 450 way to purge the genome of deleterious mutations (i.e. no clonal population senescence after 451 many generations), elegantly defining a mode of escape to Muller's ratchet (Muller 1932).

452 


\section{Acknowledgements}

454 S. Taheri acknowledge the SIE Doctoral School of the University Paris Est Créteil (France). 455 Sampling was supported by the CNRS Nouragues call and labex CEBA through the strategic 456 project DIADEMA, the Réserve de la Trinité and Our Planet Reviewed (in French Guyana), 457 CNPq, NERC, EU, Fundação Araucária, the Newton Fund and FAPESC (in Brazil), National 458 Science Foundation, USA (in Taïwan), the ECOTROP consortium and the Agence Nationale 459 des Parcs Nationaux (in Gabon), the International Joint Laboratory LUSES (in Thailand). We 460 would like to thank the Fritz Müller Museum of Blumenau for allowing collecting on their 461 property, and I. Barois, C.-H. Chang, M. Coulis, S. James, E. Lapied, and P. Lavelle, for 462 sampling specimens in the different countries covered by the COI study (dataset already 463 published in a previous paper and re-used here). 


\section{References}

Agapow PM, Burt A (2001) Indices of multilocus linkage disequilibrium. Mol Ecol Notes 1:101-102. https://doi.org/10.1046/j.1471-8278.2000.00014.x

Allendorf FW, Lundquist LL (2003) Introduction: Population biology, evolution, and control of invasive species. Conserv Biol 17:24-30. https://doi.org/10.1046/j.1523-1739.2003.02365.x Bandelt HJ, Forster P, Rohl A (1999) Median-joining networks for inferring intraspecific phylogenies. Mol Biol Evol 16:37-48. https://doi.org/10.1093/oxfordjournals.molbev.a026036 Bazin E, Mathe-Hubert H, Facon B, Carlier J, Ravigne V (2014) The effect of mating system on invasiveness: some genetic load may be advantageous when invading new environments. Biol Invasions 16:875-886. https://doi.org/10.1007/s10530-013-0544-6

Blakemore RJ (2009) Cosmopolitan earthworms — a global and historical perspective. In: Shain DH (ed) Annelids in modern biology. Wiley-Blackwell, Hoboken, pp 257-283

Bonin A, Bellemain E, Eidesen PB, Pompanon F, Brochmann C, Taberlet P (2004) How to track and assess genotyping errors in population genetics studies. Mol Ecol 13:3261-3273

Carvajal-Rodriguez A, de Una-Alvarez J, Rolan-Alvarez E (2009) A new multitest correction (SGoF) that increases its statistical power when increasing the number of tests. Bmc Bioinformatics 10. https://doi.org/20910.1186/1471-2105-10-209

Combosch DJ, Vollmer SV (2013) Mixed asexual and sexual reproduction in the Indo-Pacific reef coral Pocillopora damicornis. Ecol Evol 3:3379-3387. https://doi.org/10.1002/ece3.721

Costa D, Timmermans MJTN, Sousa JP, Ribeiro R, Roelofs D, Van Straalen NM (2013) Genetic structure of soil invertebrate populations: collembolans, earthworms and isopods. Appl Soil Ecol 68: 61-66.

Csuzdi C (2012) Earthworm species, a searchable database Opuscula Zoologica Budapest 43:97-99 

https://doi.org/10.1126/science. 887925

Cunha L et al. (2016) Soil animals and pedogenesis: the role of earthworms in anthropogenic soils. Soil Science 181:110-125. https://doi.org/10.1097/ss.0000000000000144

Cunha L, Montiel R, Novo M, Orozco-terWengel P, Rodrigues A, Morgan AJ, Kille P (2014) Living on a volcano's edge: genetic isolation of an extremophile terrestrial metazoan. Heredity 112:132-142. https://doi.org/10.1038/hdy.2013.84

De Sosa I, Marchan DF, Novo M, Diaz Cosin DJ, Giribet G, Fernandez R (2017) Insights into the origin of parthenogenesis in oligochaetes: Strong genetic structure in a cosmopolitan earthworm is not related to reproductive mode. Eur $\mathrm{J}$ Soil Biol 81:31-38. https://doi.org/10.1016/j.ejsobi.2017.06.003

Diaz Cosin DJ, Novo M, Fernandez R (2011.) Reproduction of earthworms : sexual selection and parthenogenesis. In: Karaca A (ed) Biology of earthworms. Springer-Verlag Berlin Heidelberg, pp 69-86

Dominguez J, Velando A, Aira M, Monroy F (2003) Uniparental reproduction of Eisenia fetida and E andrei (Oligochaeta : Lumbricidae): evidence of self-insemination. Pedobiologia 47:530534

Dupont L et al. (2012) Genetic signature of accidental transfer of the peregrine earthworm Pontoscolex corethrurus (Clitellata, Glossoscolecidae) in French Guiana. Eur J Soil Biol 53:7075

Dupont L, Viard F, David P, Bishop JDD (2007) Combined effects of bottlenecks and selfing in populations of Corella eumyota, a recently introduced sea squirt in the English Channel. Divers Distrib 13:808-817 
Dybdahl MF, Drown DM (2011) The absence of genotypic diversity in a successful parthenogenetic invader. Biol Invasions 13:1663-1672. https://doi.org/10.1007/s10530-0109923-4

Ehrich D (2006) AFLPDAT: a collection of R functions for convenient handling of AFLP data. Mol Ecol Notes 6:603-604. https://doi.org/10.1111/j.1471-8286.2006.01380.x

Excoffier L, Lischer HE (2010) Arlequin suite ver 3.5: a new series of programs to perform population genetics analyses under Linux and Windows. Mol Ecol Res 10: 564-567. https://doi.org/10.1111/j.1755-0998.2010.02847.x

Fernandez R, Almodovar A, Novo M, Gutierrez M, Cosin DJD (2011a) A vagrant clone in a peregrine species: Phylogeography, high clonal diversity and geographical distribution in the earthworm Aporrectodea trapezoides (Duges, 1828). Soil Biol Biochem 43:2085-2093

Fernandez R, Bergmann P, Almodovar A, Cosin DJD, Heethoff M (2011b) Ultrastructural and molecular insights into three populations of Aporrectodea trapezoides (Duges, 1828) (Oligochaeta, Lumbricidae) with different reproductive modes. Pedobiologia 54:281-290. https://doi.org/10.1016/j.pedobi.2011.04.003

Fernandez R, Novo M, Marchan DF, Cosin DJD (2016) Diversification patterns in cosmopolitan earthworms: similar mode but different tempo. Mol Phylogenet Evol 94:701-708. https://doi.org/10.1016/j.ympev.2015.07.017

Gates GE (1973) Contributions to a revision of the earthworm family Glossoscolecidae. I. Pontoscolex corethrurus (Müller, 1857). Bulletin of Tall Timbers research station 14:1-12 Hendrix PF, Callaham MA, Drake JM, Huang CY, James SW, Snyder BA, Zhang WX (2008) Pandora's Box contained bait: the global problem of introduced earthworms. Annu Rev Ecol Evol S 39:593-613

Holsinger KE, Lewis PO, Dey DK (2002) A Bayesian approach to inferring population structure from dominant markers .Mol Ecol 11:1157-1164 
Hurst LD, Peck JR (1996) Recent advances in understanding of the evolution and maintenance of sex. Trends Ecol Evol 11:A46-A52

Huson DH, Bryant D (2006) Application of phylogenetic networks in evolutionary studies. Mol Biol Evol 23:254-267. https://doi.org/10.1093/molbev/msj030

Librado P, Rozas J (2009) DnaSP v5: a software for comprehensive analysis of DNA polymorphism data. Bioinformatics 25:1451-1452

López-Legentil S, Turon X (2007) Lack of genetic variation in mtDNA sequences over the amphiatlantic distribution range of the ascidian Ecteinascidia turbinate. Mol Phylogenet Evol 45:405-408. https://doi.org/10.1016/j.ympev.2007.06.003

Lutes AA, Neaves WB, Baumann DP, Wiegraebe W, Baumann P (2010) Sister chromosome pairing maintains heterozygosity in parthenogenetic lizards. Nature 464:283-286. https://doi.org/10.1038/nature08818

Lynch M (1984) Destabilizing hybridization, general-purpose genotypes and geographic parthenogenesis. Quarterly Review of Biology 59:257-290. https://doi.org/10.1086/413902

Lynch M, Burger R, Butcher D, Gabriel W (1993) The mutational meltdown in asexual populations. J Hered 84:339-344. https://doi.org/10.1093/oxfordjournals.jhered.a111354 Müller F (1857) Description of a new earthworm (Lumbricus corethrurus). Annals and Magazine of Natural History 20:13-15

Muller HJ (1932) Some genetic aspects of sex. Am Nat 66:118-138. doi:10.1086/280418 Nei M (1987) Molecular evolutionary genetics. Colombia University Press, New York Righi G (1984) Pontoscolex (Oligochaeta : Glossoscolecidae), a new evaluation. Studies on Neotropical Fauna and Environment 19:159-177

Roman J, Darling JA (2007) Paradox lost: genetic diversity and the success of aquatic invasions. Trends Ecol Evol 22:454-464. https://doi.org/10.1016/j.tree.2007.07.002 
561 Sakai AK et al. (2001) The population biology of invasive species. Annu Rev Ecol Syst 32:305-

562

563

564

565

566

567

568

569

570

571

572

573

574

575

576

577

578

579

580

581

582

583 332

Schonswetter P, Stehlik I, Holderegger R, Tribsch A (2005) Molecular evidence for glacial refugia of mountain plants in the European Alps. Mol Ecol 14:3547-3555. https://doi.org/10.1111/j.1365-294X.2005.02683.x

Simon JC, Delmotte F, Rispe C, Crease T (2003) Phylogenetic relationships between parthenogens and their sexual relatives: the possible routes to parthenogenesis in animals. Biol J Linn Soc 79:151-163. https://doi.org/10.1046/j.1095-8312.2003.00175.x

Slatkin M (1977) Gene flow and genetic drift in a species subject to frequent local extinctions. Theor Popul Biol 12:253-262

Taheri S et al. (2018a) Complex taxonomy of the 'brush tail' peregrine earthworm Pontoscolex corethrurus. Mol Phylogenet Evol 124:60-70. https://doi.org/10.1016/j.ympev.2018.02.021

Taheri S, Pelosi C, Dupont L (2018b) Harmful or useful? A case study of the exotic peregrine earthworm morphospecies Pontoscolex corethrurus. Soil Biol Biochem 116:277-289. https://doi.org/10.1016/j.soilbio.2017.10.030

Tajima F (1989) Statistical method for testing the neutral mutation hypothesis by DNA polymorphism. Genetics 123:585-595.

Vekemans X, Beauwens T, Lemaire M, Roldan-Ruiz I (2002) Data from amplified fragment length polymorphism (AFLP) markers show indication of size homoplasy and of a relationship between degree of homoplasy and fragment size. Mol Ecol 11:139-151

Vorburger C, Lancaster M, Sunnucks P (2003) Environmentally related patterns of reproductive modes in the aphid Myzus persicae and the predominance of two 'superclones' in Victoria, Australia. Mol Ecol 12:3493-3504. https://doi.org/10.1046/j.1365-294X.2003.01998.X 
584 Vos P, Hogers R, Bleeker M, Reijans M, van de Lee T, Hornes M, Frijters A, Pot J, Peleman J, 585 Kuiper $M$ et al (1995) AFLP: a new technique for DNA fingerprinting. Nucleic Acids Res $586 \quad 23: 4407-14$

587 Zenger KR, Richardson BJ, Vachot-Griffin AM (2003) A rapid population expansion retains 588 genetic diversity within European rabbits in Australia. Mol Ecol 12:789-794. 589 https://doi.org/10.1046/j.1365-294X.2003.01759.x

590

591 
Fig. 1: Locations of the P. corethrurus L1 specimens used in the study and COI haplotype 595 network based on 478 sequences in 49 locations; with the name of the countries where samples were collected in bold (for details about each site, see Table S1). Each colour represents a 597 different haplotype and pie charts in the map display the relative frequencies for a given locality 598 of each of the haplotypes. The white small circles indicate the presence of islands that could 599 not be visualized otherwise. The location of the 12 populations used in the population genetics 600 analysis are indicated by their code in the map. Codes of populations from the native range (i.e.

601 Guayana Shield) are underlined. In the network, connecting lines show mutational pathways 602 among haplotypes. Only one mutation separates the haplotypes, unless the number of mutation 603 is indicated.

604

605

Fig. 2: Neighbor-Net networks done on AFLP profiles with Splitstree based on Nei's genetic 606 distance matrix for 12 populations of $P$. corethrurus L1. Populations from the presumed native 607 range are in black while populations from the introduced range are in blue. The country of 608 origin of each population is indicated by the following codes : GUY - French Guiana, BRA 609 Brazil, MEX - Mexico, GAB - Gabon, THA - Thailand.

610 
Table 1: Overall genetic variability in 12 P. corethrurus L1 populations, based on 318 polymorphic AFLP markers and 633 bp fragment of the COI gene.

\begin{tabular}{|c|c|c|c|c|c|c|c|c|c|c|c|c|c|}
\hline & \multirow[b]{2}{*}{ Sites } & \multicolumn{5}{|c|}{ Native range } & \multicolumn{7}{|c|}{ Introduced range } \\
\hline & & CAY & MIT & PARA & PARB & PARC & CAX & BEL & JNL & ORL & TLC & LOP & $\mathrm{CHG}$ \\
\hline \multirow{10}{*}{ AFLP } & $\mathrm{N}_{\mathrm{AFLP}}{ }^{\mathrm{a}}$ & 17 & 20 & 19 & 8 & 13 & 18 & 21 & 22 & 24 & 9 & 20 & 35 \\
\hline & $\mathrm{VM} \%{ }^{\mathrm{b}}$ & 52.284 & 31.472 & 21.574 & 22.335 & 46.701 & 48.223 & 41.878 & 51.523 & 22.589 & 28.173 & 2.030 & 34.518 \\
\hline & $\mathrm{DW}\left(\right.$ from means) ${ }^{\mathrm{b}}$ & 1804 & 830.7 & 362.2 & 406.1 & 516.6 & 708.9 & 570.7 & 354.1 & 426.1 & 467.2 & 692.7 & 471.1 \\
\hline & $\mathrm{NoH}^{\mathrm{c}}$ & 17 & 17 & 16 & 7 & 13 & 14 & 21 & 22 & 21 & 9 & 3 & 25 \\
\hline & Genotype diversity ${ }^{\mathrm{d}}$ & 1 & 0.979 & 0.965 & 0.964 & 1 & 0.935 & 1 & 1 & 0.978 & 1 & 0.416 & 0.973 \\
\hline & Gene diversity $^{\mathrm{d}}$ & 0.165 & 0.112 & 0.052 & 0.087 & 0.163 & 0.138 & 0.132 & 0.168 & 0.083 & 0.113 & 0.012 & 0.110 \\
\hline & PCLP $^{d}$ & 0.91 & 0.97 & 0.99 & 1.00 & 0.94 & 0.96 & 0.93 & 0.88 & 0.98 & 0.99 & 1.00 & 0.96 \\
\hline & $\mathrm{I}_{\mathrm{A}}^{\mathrm{d}}$ & 6.78 & 6.82 & 11.91 & 18.51 & 2.54 & 22.34 & 12.77 & 2.23 & 13.37 & 42.52 & 1.29 & 11.98 \\
\hline & $\bar{r}_{\mathrm{d}}^{\mathrm{d}}$ & 0.03 & 0.06 & 0.15 & 0.21 & 0.01 & 0.12 & 0.08 & 0.01 & 0.16 & 0.39 & 0.21 & 0.09 \\
\hline & $\operatorname{LD}(\%)^{\mathrm{d}}$ & 8.66 & 14.78 & 8.32 & 9.67 & 8.49 & 16.04 & 19.84 & 4.06 & 34.17 & 19.64 & 0.00 & 20.12 \\
\hline \multirow{6}{*}{$\mathrm{COI}$} & $\mathrm{N}_{\mathrm{COI}}^{\mathrm{a}}$ & 12 & 64 & 16 & 16 & 15 & 12 & 15 & 17 & 13 & 9 & 20 & 60 \\
\hline & $\mathrm{NPS}^{\mathrm{e}}$ & 6 & 10 & 0 & 0 & 0 & 11 & 6 & 5 & 0 & 6 & 0 & 1 \\
\hline & Number of haplotype & 2 & 4 & 1 & 1 & 1 & 4 & 2 & 2 & 1 & 2 & 1 & 2 \\
\hline & Haplotype diversity & 0.530 & 0.693 & 0 & 0 & 0 & 0.561 & 0.133 & 0.221 & 0 & 0.500 & 0 & 0.381 \\
\hline & $P_{i}(\text { per site })^{f}$ & 0.00503 & 0.00671 & 0 & 0 & 0 & 0.00426 & 0.00126 & 0.00174 & 0 & 0.00474 & 0 & 0.00060 \\
\hline & Tajima's D ${ }^{g}$ & $2.294^{*}$ & $2.762 * *$ & - & - & - & -1.080 & $-1.983 *$ & -0.744 & - & 1.566 & - & 0.999 \\
\hline
\end{tabular}

$\bar{a}$ The number of individuals that have been genotyped using AFLPs or sequenced for COI are given by $\mathrm{N}_{\mathrm{AFLP}}$ and $\mathrm{N}_{\text {COI }}$ respectively. ${ }^{\mathrm{b}}$ Percentage of variable markers $\left(\mathrm{VM} \%\right.$ ) and Frequency-down-weighted marker values (DW) were computed using the AFLP dataset with clones. ${ }^{\mathrm{c}}$ The number of different AFLP genotypes in the population is given by NoH. ${ }^{d}$ For the computation of genotype diversity, gene diversity, proportion of compatible locus pairs (PCPL), indexes of association ( $\mathrm{I}_{\mathrm{A}}$ and $\bar{r}_{\mathrm{d}}$ ) and gametic disequilibrium (LD), clones were removed from the AFLP dataset; significant values $(\mathrm{P}<0,002)$ are shown in bold. ${ }^{\mathrm{e}} \mathrm{NPS}$ correspond to the number of COI polymorphic sites. ${ }^{\mathrm{f}} \mathrm{P}_{\mathrm{i}}$ correspond to the COI nucleotide diversity. ${ }^{\mathrm{g}}$ For Tajima's $\mathrm{D}$, significance is given by: ${ }^{*} \mathrm{P}<0.05, * * \mathrm{P}<0.01$. 
Table 2: Analysis of molecular variance (AMOVA) of COI and AFLP (in italics) genotypes for 5 populations from the presumed native range and 7 populations from the introduced range of $P$. corethrurus.

\begin{tabular}{|c|c|c|c|c|}
\hline & Variance components & $\%$ of total variation & P-value & $\Phi$ statistics \\
\hline \multirow[t]{2}{*}{ Among groups (native versus introduced) } & 0.142 & 11.22 & 0.194 & $\Phi_{\mathrm{CT}}=0.112$ \\
\hline & 1.49 & 5.16 & 0.001 & $\Phi_{C T}=0.052$ \\
\hline \multirow[t]{2}{*}{ Among populations within groups } & 0.316 & 24.91 & 0.000 & $\Phi_{\mathrm{SC}}=0.281$ \\
\hline & 9.08 & 31.26 & 0.000 & $\Phi_{S C}=0.330$ \\
\hline \multirow[t]{2}{*}{ Among all populations } & 0.809 & 63.87 & 0.000 & $\Phi_{\mathrm{ST}}=0.361$ \\
\hline & 18.47 & 63.58 & 0.000 & $\Phi_{S T}=0.364$ \\
\hline
\end{tabular}


Figure1:

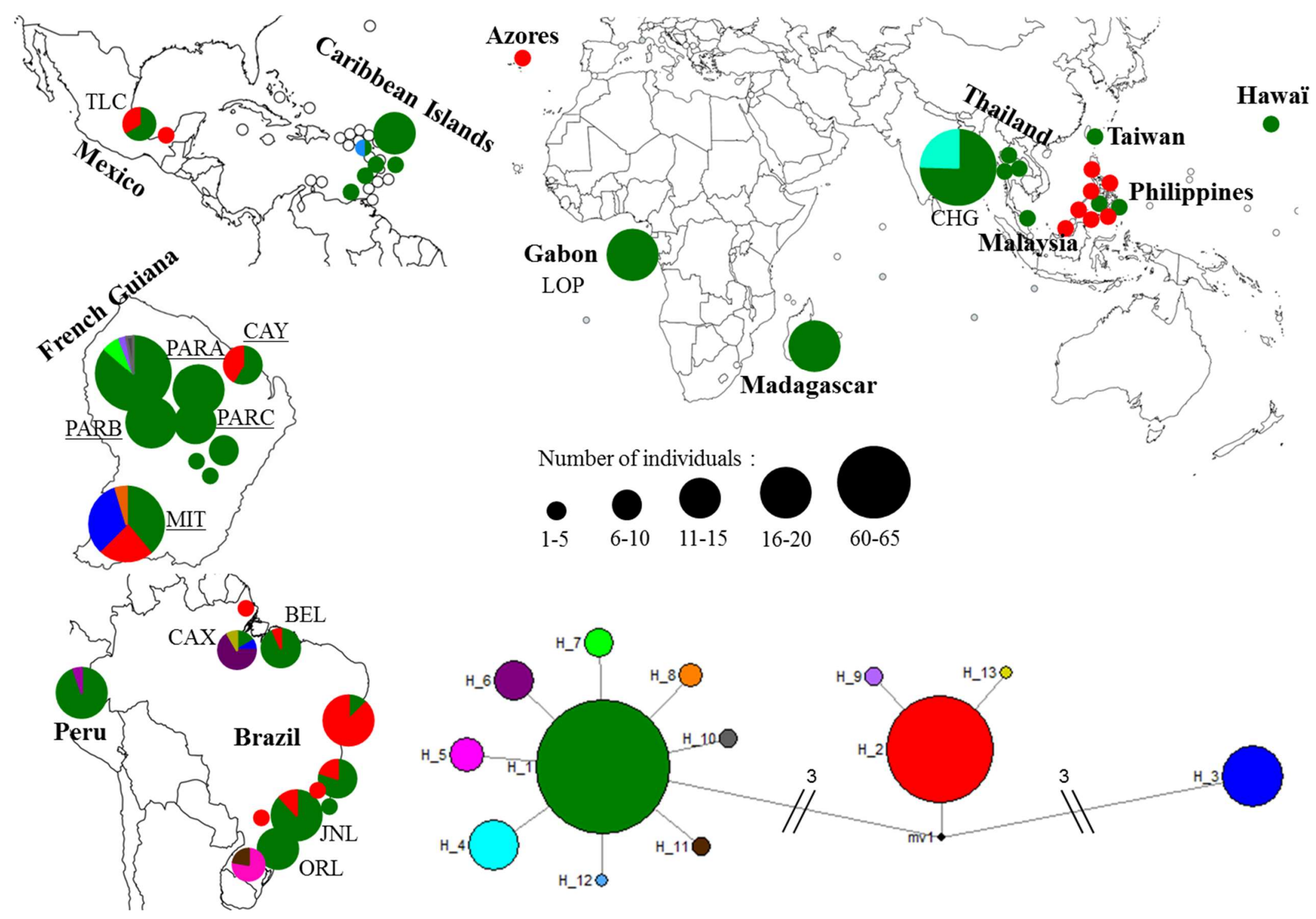


Figure 2

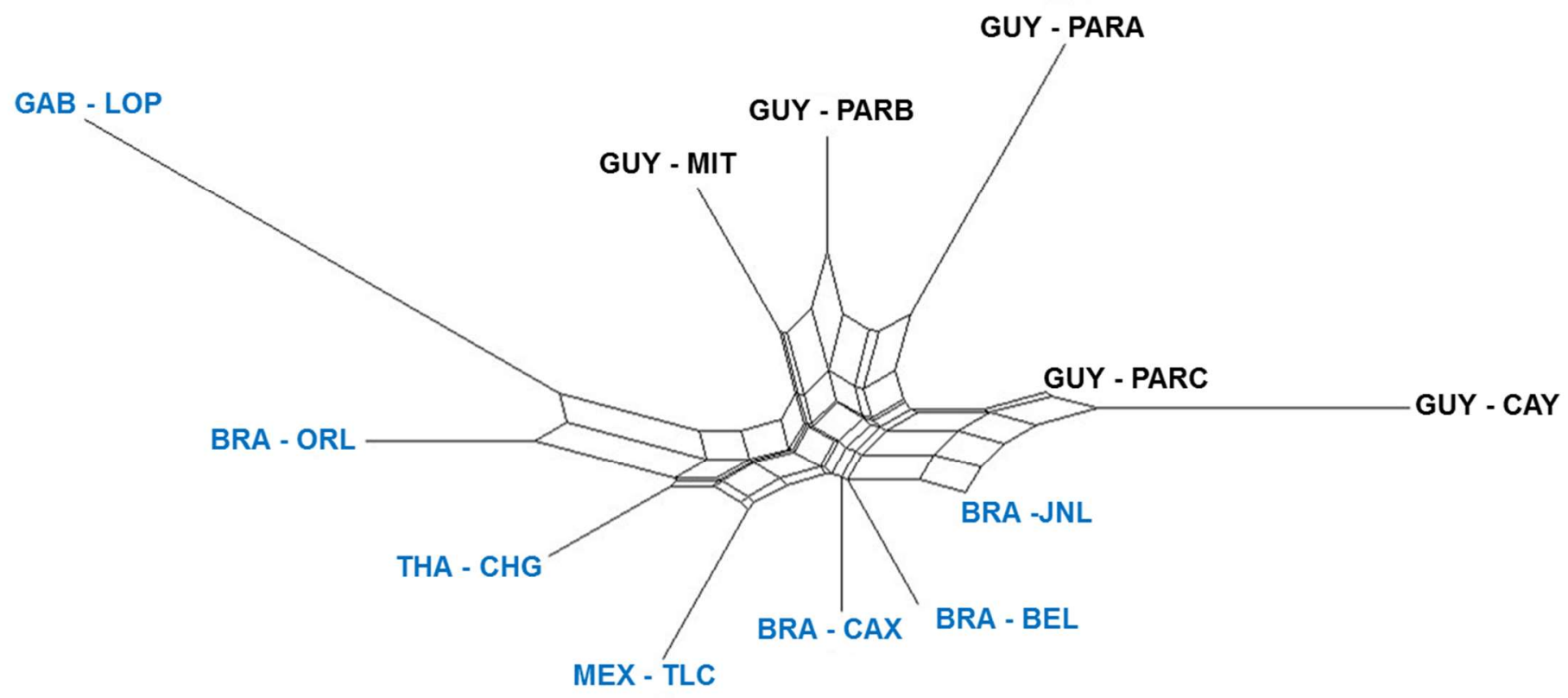

